\title{
The effects of flavor preexposure and test interval on conditioned taste aversions in rats
}

\author{
PHILIPP J. KRAEMER \\ State University of New York at Binghamton, Binghamton, New York \\ and \\ KLAUS-PETER OSSENKOPP \\ The University of Western Ontario, London, Ontario, Canada
}

\begin{abstract}
The effect of prior experience with a flavor, which was either the same as the conditioned stimulus (CS) or different, was examined at 1- and 21-day test intervals. A single brief preexposure to a flavor different from the CS produced attenuated taste aversions at the 1-day interval, but not at the 21-day interval. Conversely, experience with the same flavor used as the CS produced attenuated aversions at both 1- and 21-day intervals. This extends the empirical generality of the preexposure-test-interval relationship reported by Kraemer and Roberts (1984) by showing that the effect is not restricted to the specific procedures employed in that study.
\end{abstract}

It has been found consistently that rats exhibit stronger conditioned taste aversions to novel flavors than to flavors previously experienced (Elkins, 1973; Revusky \& Garcia, 1970; Vogel \& Clody, 1972). It has also been shown that prior experience with a flavor different from the CS can similarly attenuate a conditioned aversion (Dawley, 1979; Kraemer \& Roberts, 1984). The conventional interpretation of the preexposure effect has been that a prior flavor experience in some way disrupts the acquisition of a CS aversion, and a variety of mechanisms have been offered to account for this putative disruption (Best \& Barker, 1977; Best \& Gemberling, 1977; Kalat \& Rozin, 1973).

A series of experiments by Kraemer and Roberts (1984) provided data that seem to challenge this view. These experiments compared the influence of same-flavor and different-flavor preexposure on the strength of conditioned flavor aversions, tested either 1 or 21 days after conditioning. It was found that both types of preexposure produced attenuated aversions at the 1-day test interval. After a 21-day interval, however, the two forms of preexposure were found to have differential effects: same-flavor preexposure still produced attenuated aversions, whereas different-flavor preexposure did not. Subjects in the latter condition showed aversions as strong as those found in subjects not preexposed. Also, there was evidence that with some taste CSs (e.g., chocolate milk) the attenuating effect of same-flavor preexposure declined significantly over a 21 -day interval.

These unexpected results are difficult to explain in terms of the traditional view of flavor preexposure. If the ac-

This research was supported by Natural Sciences and Engineering Research Council Grant No. U0151 to the second author. Requests for reprints should be sent to K.-P. Ossenkopp, Department of Psychology, University of Western Ontario, London, Ontario, Canada N6A 5 C2. quisition of an aversion is disrupted by prior experience, then the impact of this disruption (i.e., attenuated aversions) should be apparent at any test interval. The interaction between test interval and the effect of flavor preexposure suggests that acquisition may not be disrupted, and therefore that some alternative mechanism may be responsible for the attenuation.

Before such alternative mechanisms of the preexposure effect are seriously considered, it seems prudent to evaluate further the empirical generality of the effects reported by Kraemer and Roberts (1984). In that study, preexposure consisted of $30 \mathrm{~min}$ access to flavored liquids on each of the 3 successive days prior to conditioning. A twobottle preference test was then used to measure aversions. It is important to determine whether an alternative preexposure treatment and test procedure will show an interaction between preexposure and test interval. For example, it has been shown that a single brief preexposure to a flavor given less than $4 \mathrm{~h}$ before conditioning can significantly reduce aversion strength (Best \& Gemberling, 1977). It would be of value to know whether this preexposure treatment is as effective with different-flavor preexposure as it is with same-flavor preexposure, and whether the effect is dependent upon test interval. If the effect obtained with this procedure is similar to the effect obtained with the procedure used by Kraemer and Roberts (1984), we can be more confident that the preexposure-test-interval relationship is a general one and does not represent a procedural artifact.

\section{METHOD}

Thirty-six male Long-Evans rats (Charles River), 100 days of age, were randomly assigned to six experimental conditions, with 6 rats in each group. They were placed on a 23.5-h water deprivation schedule 1 week prior to the start of the experiment. All rats were housed in individual wire cages and were maintained in the same vivarium, which 
also served as the test room. On the conditioning day, Groups MM-1 and MM-21 were given $4 \mathrm{ml}$ of chocolate milk ( $2 \%$ butterfat), diluted $50 \%$ by volume with tap water, and Groups SM- 1 and SM-21 were given $4 \mathrm{ml}$ of $.1 \%(\mathrm{w} / \mathrm{v})$ sodium saccharin solution. Groups $\mathrm{M}-1$ and $\mathrm{M}-21$ were given no preexposure. The liquids were dispensed at room temperature in metal dishes measuring $7.5 \mathrm{~cm}$ (length) $\times 5 \mathrm{~cm}$ (width) $\times$ $2.5 \mathrm{~cm}$ (depth). Each dish was secured to the inside of the cage and was removed 30 min after placement; by this time all rats had consumed the entire contents of their dishes. After a 3.5-h interval, all rats were given $4 \mathrm{ml}$ of the chocolate milk CS, again dispensed in the metal dishes. The dishes were removed 30 min after placement, by which time all rats had consumed the contents. Each rat was then given an ip injection of a $0.15 \mathrm{M} \mathrm{LiCl}$ solution, administered at a dosage level of $20 \mathrm{ml} / \mathrm{kg}$ body weight. No additional liquids were provided on the conditioning day. Testing took place either 1 day (Groups M-1, MM-1, and SM-1) or 21 days (Groups M-21, MM-21, and SM-21) after conditioning. On the test day, $50 \mathrm{ml}$ of the chocolate milk CS was presented in graduated centrifuge tubes, which were attached to the front of each cage. The consumption test lasted $30 \mathrm{~min}$. Rats in the 21-day interval groups were given free access to water from the day following conditioning until 8 days prior to their test day, at which time they were again placed on a 23.5-h deprivation schedule. The amount of CS consumed on the test days was recorded to the nearest $0.5 \mathrm{ml}$.

\section{RESULTS}

The mean volume of chocolate milk CS consumed on test days by each group is presented in Figure 1. It can be seen that substantial differences in mean intake appeared across the conditions. A factorial analysis of variance was performed on these data, with factors consisting of preexposure experience and test interval. The main effect of preexposure experience was found to be significant $[F(2,30)=12.45, p<.001]$, and the preexposure

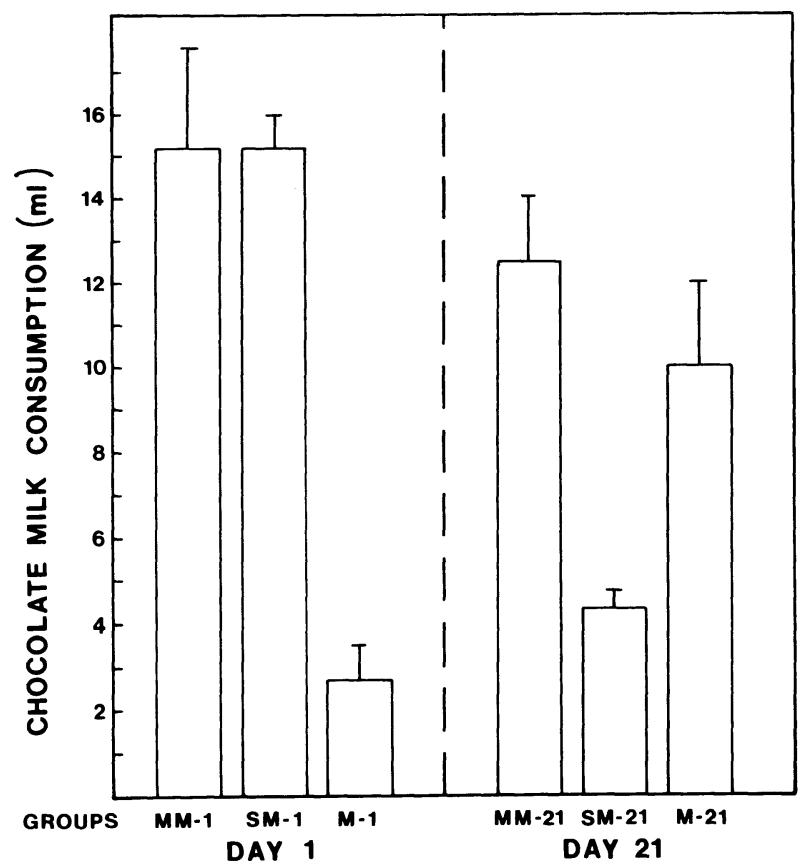

Figure 1. Group mean chocolate milk consumption for animals presented with the chocolate milk 1 or 21 days after the conditioning trial. The error bars are standard errors of the mean. $\times$ test interval interaction was also significant $[F(2,30)$ $=18.27, p<.001]$. Individual group mean comparisons were evaluated with a Newman-Keuls analysis $(\alpha=.05)$. It was found that at the 1-day interval Groups SM-1 and MM-1 drank comparable amounts, and both groups drank significantly more than Group M-1. At the 21-day interval, Groups MM-21 and M-21 drank comparable amounts, and both drank significantly more than Group SM-21. With respect to the effects of test interval on each of the three preexposure conditions, it was found that Group SM-21 showed a significant decrease in consumption relative to Group SM-1; Group M-21 drank signifiantly more than Group M-1; and Groups MM-21 and MM-1 were not significantly different.

\section{DISCUSSION}

The results of this experiment extend the generality of the relationship between flavor preexposure and test interval length reported by Kraemer and Roberts (1984). It was once again found that same-flavor and different-flavor preexposure had differential effects at short and long test intervals. When testing occurred 1 day after conditioning, both forms of preexposure reduced the strength of a conditioned aversion, relative to a nonpreexposed control group. After a 21-day interval, however, same-flavor preexposure continued to have an attenuating effect, whereas different-flavor preexposure no longer reduced aversion strength. Thus, comparable preexposure effects have now been demonstrated with substantially different procedures: with a single brief preexposure given shortly before conditioning and tested with a one-bottle preference test, in the present experiment, and with multiple, prolonged preexposures given 1 day prior to conditioning and tested with a two-bottle preference test, in the Kraemer and Roberts (1984) study. This strongly suggests that the preexposure-test-interval relationship is reliable and may represent a general conditioned taste aversion phenomenon.

The one anomalous finding from this experiment is that the nonpreexposed control group tested after a 21-day interval exhibited weaker aversions than those of a comparable group tested at a 1-day interval. This would suggest that forgetting occurred among nonpreexposed subjects tested over an extended interval. This result is inconsistent with previous failures to note any forgetting of conditioned taste aversions (Dragoin, Hughes, Devine, \& Bentley, 1973; Kalat, 1977; Steinert, Infurna, \& Spear, 1980). This forgetting could have resulted from the control subjects' acquiring relatively weak aversions which gradually diminished over the 21-day interval. Then with the one-bottle test, in which avoidance behavior is confounded with deprivation level, the weak aversions may have been obscured. Thus, with a two-bottle preference test, the decrease in aversion strength in nonpreexposed animals may not have appeared.

\section{REFERENCES}

BEST, M. R., \& BARKER, L. M. (1977). The nature of "learned safety" and its role in the delay of reinforcement gradient. In L. M. Barker, M. R. Best, \& M. Domjan (Eds.), Learning mechanism in food selection. Waco, TX: Baylor University Press.

BEST, M. R., \& GEMBERLING, G. A. (1977). Role of short-term processes in the conditioned stimulus preexposure effect and the delay of reinforcement gradient in long-delay taste aversion learning. Journal of Experimental Psychology: Animal Behavior Processes, 3, 243-263.

DAWLEY, J. M. (1979). Generalization of the CS-preexposure effect transfers to taste aversion learning. Animal Learning \& Behavior, 7, 23-24.

Dragoin, W., Hughes, G., Devine, M., \& Bentley, J. (1973). Longterm retention of conditioned taste aversions: Effects of gustatory interference. Psychological Reports, 33, 511-514.

Elkins, R. L. (1973). Attenuation of drug-induced bait shyness to a 
palatable solution as an increasing function of its availability prior to conditioning. Behavioral Biology, 9, 221-226.

KALAT, J. W. (1977). Status of "learned safety" or "learned noncorrelation" as a mechanism in taste aversion learning. In L. M. Barker, M. R. Best, \& M. Domjan (Eds.), Learning mechanisms in food selection. Waco, TX: Baylor University Press.

Kalat, J. W., \& RozIN, P. (1973). "Learned safety" as a mechanism in long delay taste aversion learning in rats. Journal of Comparative \& Physiological Psychology, 83, 198-207.

Kraemer, P. J., \& Roberts, W. A. (1984). The influence of flavor preexposure and test interval on conditioned taste aversions in the rat. Learning \& Motivation, 15, 259-278.
REVUSKY, S. H., \& GARCIA, J. (1970). Learned associations over long delays. In G. H. Bower \& J. J. Spence (Eds.), The psychology of learning and motivation: Advances in research and theory (Vol. 4). New York: Academic Press.

Steinert, P. A., Infurna, R. N., \& SPEAR, N. E. (1980). Long-term retention of a conditioned taste aversion in preweanling and adult rats. Animal Learning \& Behavior, 8, 375-381.

Vogel, J. R., \& Clody, D. E. (1972). Habituation and conditioned food aversion. Psychonomic Science, 28, 275-276.

(Manuscript received for publication February 11, 1986.) 